Geophysical Research Abstracts,

Vol. 11, EGU2009-10782, 2009

EGU General Assembly 2009

(C) Author(s) 2009

\title{
The Quest for the Africa-Eurasia plate boundary West of the Strait of Gibraltar
}

\author{
N. Zitellini and the SWIM Team \\ CNR, ISMAR-BO, Bologna, Italy (nevio.zitellini@bo.ismar.cnr.it)
}

A new swath bathymetry compilation of the Gulf of Cadiz Area and SW Iberia is presented. The new map is the result of a collaborative research performed after year 2000 by teams from 7 European countries and 14 research institutions. This new dataset allow for the first time to present and to discuss the missing link in the plate boundary between Eurasia and Africa in the Central Atlantic. A set of almost linear and sub parallel dextral strike-slip faults, the SWIM Faults (SWIM is the acronym of the ESF EuroMargins project "Earthquake and Tsunami hazards of active faults at the South West Iberian Margin: deep structure, high-resolution imaging and paleoseismic signature") was mapped using a the new swath bathymetry compilation available in the area. The SWIM Faults form a narrow band of deformation over a length of $600 \mathrm{~km}$ coincident with a small circle centred on the pole of rotation of Africa with respect to Eurasia, This narrow band of deformation connects the Gloria Fault to the Rif-Tell Fault Zone, two segments of the plate boundary between Africa and Eurasia. In addition, the SWIM faults cuts across the Gulf of Cadiz, in the Atlantic Ocean, where the 1755 Great Lisbon earthquake, $\mathrm{M} \sim 8.5-8.7$, and tsunami were generated, providing a new insights on its source location.

\section{SWIM Team:}

E. Gràcia (2), L. Matias (3), P. Terrinha (4), M.A. Abreu (5), G. DeAlteriis(6), J.P. Henriet (7), J.J. Dañobeitia (2), D.G. Masson (8), T. Mulder (9), R. Ramella (10), L. Somoza (11) and S. Diez (2)

(2) Unitat de Tecnologia Marina (CSIC), Centre Mediterrani d'Investigacions Marines i Ambientals, Barcelona, Spain

(3) Centro Geofísica da Universidade de Lisboa (CGUL, IDL), Lisboa, Portugal

(4) National Institute for Engineering, Technology and Innovation (INETI, LATTEX), Departamento de Geologia Marinha, Amadora, Portugal

(5) Estrutura de Missão para a Extensão da Plataforma Continental, Lisboa, Portugal

(6) Geomare Sud IAMC, CNR, Napoli, Italy

(7) Renard Centre of Marine Geology, Dpt. Geology and Soil Science, Gent University, Gent, Belgium

(8) National Oceanography Centre, European Way, Southampton, United Kingdom

(9) Département de Géologie et Océanographie, Talence Cedex, France

(10) Department for the Development of Marine Technology and Research, Istituto Nazionale di Oceanografia e di Geofisica Sperimentale (OGS), Sgonico, Italy

(11) Geología Marina, Instituto Geológico y Minero de España, Madrid, Spain 